- Orijinal Makale

\title{
Kronik spontan ürtikerde omalizumab tedavisinin etkinliği: Retrospektif bir çalışma
}

\section{The efficacy of omalizumab therapy in chronic spontaneous urticaria: A retrospective analysis}

\author{
Fatma Elif YILDIRIM* 回
}

Sanko Üniversitesi Sani Konukoğlu Araştırma ve Uygulama Hastanesi, Dermatoloji Anaiblim Dalı, Gaziantep/TÜRKIYE

\section{Öz}

Amaç: Bu çalışmada tedaviye dirençli kronik spontan ürtiker (KSÜ) nedeni ile omalizumab tedavisi kullanan hastaların klinik ve demografik özelliklerinin yanısıra omalizumab etkinliği ile yan etkilerinin geriye dönük olarak değerlendirilmesi amaçlanmıştır.

Gereç ve Yöntemler: Kliniğimizde 2014-2017 yılları arasında H1-antihistaminiklere direnç nedeni ile 300 mg/ay subkutan omalizumab başlanan KSÜ hastalarının kayıtlı bilgisayar verileri taranarak retrospektif olarak incelendi. Hiç ürtikeryal plağı ve kaşıntısı olmayanlar tam yanıtlı, tedavi başlangııına göre hayat kalitesi artan ve semptomlarında belirgin iyileşme olanlar kısmi yanıtlı, semptomlarında hiç iyileşme olmayanlar yanıtsız olarak kabul edildi.

Bulgular: Tedaviye dirençli KSÜ nedeniyle omalizumab verilen 71 (41 K, 30 E) hasta çalışmaya dahil edildi. Bu hastaların

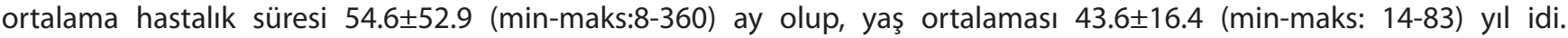
Omalizumab tedavisi 3. ayı sonunda hastaların yapılan değerlendirilmesinde, 14 (19.7\%) hastada tam yanıt, 36 (50.7\%) hastada kısmı yanıt görülürken, 21 (\%29,6) hastada yanıt alınamadı. Başlangıç total IgE ve CRP düzeyleri, hastalık süresi, hasta yaşı, cinsiyeti, astım öyküsü ve immünsupresif kullanım öyküsü açısından 3. ay sonu omalizumab tedavisi yanıt grupları arasında herhangi bir istatistiksel farklılık tespit edilmedi ( $p>0.05$ ). Hastalarda ciddi bir yan etki saptanmadı.

Sonuç: Bu çalışmada, KSÜ nedeniyle takip edilip omalizumab kullanılan hastalarda, omalizumab tedavisinin etkin ve güvenilir olduğunu tespit ettik.

Anahtar kelimeler: ürtiker; omalizumab; immunoglobulin e

Sorumlu Yazar*: Fatma ElifYıldıım, Sanko Üniversitesi Sani Konukoğlu Araştırma ve Uygulama Hastanesi, Dermatoloji Anaiblim Dalı, Gaziantep/TÜRKiYE E-posta: elifalper27@gmail.com 


\begin{abstract}
Aim: In this study, it was aimed to evaluate the clinical and demographic features of patients using omalizumab therapy for treatment-resistant CSU, as well as the efficacy and side effects of omalizumab retrospectively.
\end{abstract}

Material and Methods: In our clinic, we retrospectively checked the computer data of CSU patients who began subcutaneous omalizumab 300 mg / month due to H1-antihistamin resistance between 2014 and 2017. Those without urticaria plaque and itching were considered to be a complete response; those with improved quality of life relative to the onset of treatment and significant improvement in their symptoms were considered to be a partial response; and those with no improvement in symptoms were considered to be unresponsive.

Results: Seventy-one (41 F, 30 M) patients who received omalizumab for treatment-resistant CSU were included in the study. The mean disease duration of these patients was $54.6 \pm 52.9$ (min-max: 8-360) months and the mean age was 43.6 \pm 16.4 (min-max: 14-83) years. In patient evaluation at the end of the third month of treatment with omalizumab, 14 (19.7\%) patients had complete response, 36 (50.7\%) patients had partial response, whereas 21 (29.6 \%) patients had no response. At the end of the 3rd month there was no statistical difference between the omalizumab treatment response groups in terms of baseline total IgE and CRP levels, disease duration, patient age, sex, history of asthma, and history of immunosuppressive use. There were no significant side effects in the patients.

Conclusion: In this study, we found that treatment with omalizumab was effective and safe in patients who were being followed up due to CSU and used omalizumab.

Keywords: omalizumab, urticaria, immunglobulin e

\section{Giriş}

Heterojen bir hastalık olan ürtikerin klinik görünümüne göre değişik alt tipleri olsa da, gözlenen ortak deri reaksiyonu kaşıntılı eritemli ödemli ürtikeryal deri lezyonları ve/veya anjiyoödemdir.[1,2] Yaklaşık olarak insanların \%9'unun tüm hayatı boyunca en az bir kez ürtiker atağı geçirdiği ve bu olguların da $\% 0,1-1$ 'inde 6 haftadan daha uzun süreli ürtikeryal lezyonlar ile karakterize kronik ürtiker (KÜ) geliştiği düşünülmektedir. En sık görülen ürtiker tipi olan ve herhangi bir dış uyaran olmaksızın meydana gelen spontan ürtiker tablosuna kronik spontan ürtiker (KSÜ) adı verilmektedir.[2] KSÜ tablosunun oluşumunda gıda ve ilaçlara karşı intolerans reaksiyonları, enfeksiyonlar ve otoreaktif mekanizmalar gibi altta yatan çeşitli faktörlerin rol oynadığı düşünülmektedir.[1,2]

Kronik ürtiker klavuzu, KSÜ tedavisinde üç basamaklı bir yaklaşım önermektedir. Birinci basamakta, ikinci kuşak antihistaminik ilaçlar kullanımını, bu tedaviye yanıt vermeyen hastalarda ikinci basamakta dört katına kadar doz artırımını önermektedir. Semptomların devam etmesi halinde ise üçüncü basamak tedavide omalizumab veya siklosporin A veya lökotrien reseptör antagonisti (LTRA) kullanımı önermektedir.[3] Omalizumab, serum immunglobulin E (lgE)'lerine bağlanarak, lgE'nin mast hücre ve dolaşan bazofiller üzerindeki yüksek afiniteli lgE re- septörüne bağlanmasına engel olmaktadır. Böylelikle IgE'nin efektör fonksiyonlarını inhibe ederek selüler medyatörlerin salınımını inhibe etmektedir.[4] Sonuçta omalizumab duyarlı allerjenle tetiklenen efektör hücre aktivasyonunu önlemekte ve allerjenlere karşı gelişen hem erken hem de geç faz yanıtlarını azaltmaktadır.[5] Güvenilirlik açısından bakıldığında ise bir çok derleme ve meta-analizde omalizumab tedavisinin genel yan etki insidansını arttırmadığı gösterilmiştir.[6,7]

Literatür incelendiğinde bu konuda gerçek yaşam deneyimini sunan, Güneydoğu Anadolu Bölgesinde yapılmış az sayıda çalışma olduğu saptanmıştır.[8,9] Çalışmamızda, 3. basamak bir sağlık kurumu olan hastanemizde tedaviye dirençli KSÜ nedeni ile omalizumab tedavisi kullanan hastaların klinik ve demografik özelliklerinin yanısıra omalizumab etkinliği ile yan etkilerinin değerlendirilmesi amaçlanmıştır.

\section{Gereç ve Yöntemler}

Kliniğimizde 2014-2017 yılları arasında tedaviye direnç nedeni ile omalizumab başlanan KSÜ hastaların kayıtlı bilgisayar verileri taranarak omalizumab etkinliğinin ve yan etkilerinin retrospektif olarak incelenmesi planlandı. Hastaların dosyalarından yaş, cinsiyet, hastalık süresi, daha önce kullanılan tedaviler ve labarotuvar testlerinden tam kan sayımı ve total lgE düzeylerinin kaydedilmesi planlandı. 
Omalizumab tedavisi başlanmadan önce tüm hastaların en az altı ay süre ile ikinci kuşak antihistaminik tedavisi kullanmış olması gerekmektedir. İkinci kuşak antihistaminik olarak desloratadin, loratadin, setirizin, levosetirizin, feksofenadin veya rupatadinden en az biri standart dozda kullanılmaktadır. Bu tedavilere rağmen ürtiker semptomları kontrol altına alınamayan KSÜ'li hastalar antihistaminik tedavisine dirençli kabul edilmektedir ve omalizumab tedavisi, subkutan enjeksiyon olacak şekilde başlanmaktadır.

Hastalar aylık kontrollerinde omalizumab sonrası enjeksiyon yerinde ağrı, morarma, şişme, kızarıklık ve kaşıntı gibi geçici enjeksiyon bölgesi reaksiyonları açısından ve nazofarenjit, üst solunum yolu infeksiyonu, baş ağrısı ile sinüzit gibi yan etkiler açısından değerlendirilmektedir.

Kliniğimizde Omalizumab dozu şu an için Sağlık Bakanlığı tarafından KSÜ için geri ödeme kapsamında olan 300 mg/ay olarak verilmektedir. Tedaviye yanıtsız hastalar için sağlık bakanlığına doz artırımı için başvuruda bulunulmaktadır.

Hastalar tedavi yan etkisi ve etkinlik açısından aylık olarak dermatoloji uzman hekimi tarafından değerlendirilmektedir. 3 ayıık tedavi sonrasında hiç ürtikeryal plağı ve kaşıntısı olmayanlar tam yanıtlı, tedavi başlangıcına göre hayat kalitesi artan, ürtikeryal plağı ve kaşıntısı azalan ancak hala tam geçmeyen hastalar kısmi yanıtlı, semptomlarında hiç iyileşme olmayanlar yanıtsız olarak kabul edilmiştir. Bu çalışma için etik kurul izni Sanko Üniversitesi Girişimsel Olmayan Araştırmalar Etik Kurulu'ndan alınmıştır. Hastalara aydınlatılmış onam belgesi imzalatılmıştır.

\section{İstatistiksel Analiz}

Tanımlayıcı istatistik olarak; ölçümle belirtilen sürekli değişkenler için ortalama ve standart sapma veya medyan ve minimum-maksimum değerleri, nitel değişkenler için frekans ve yüzde değerleri verilmiştir. Grup karşılaştırmalarında; ölçümle belirtilen sürekli değişkenler için parametrik test koşullarının sağlanması durumunda iki ortalama arasındaki farkın önemlilik testi, parametrik test koşullarının sağlanmadığı durumlarda Mann-Whitney U testi kullanılmıştır. Nitel değişkenlerin grup karşılaştırmaları için ki-kare testi kullanılmıştır.

\section{Bulgular}

Çalışmaya alınan hastaların demografik ve klinik özellikleri Tablo 1'de belirtildi. Tedaviye dirençli KSÜ nedeniyle omalizumab verilen 71 (41 K, $30 \mathrm{E}$ ) hasta çalışmaya dahil edildi. Bu hastaların ortalama hastalık süresi 54.6 \pm 52.9 (min-maks:8-360) ay olup, yaş ortalaması 43.6 16.4 (min-maks: 14-83) yıl idi. Ortalama omalizumab kullanma süresi 6.2 \pm 4.1 (min-maks:2-19) ay idi. Hastaların başlangıç total IgE düzeyleri ortalaması 6.2 4 .1 (min-maks:18-5660) IU/ml idi. $27(34,2)$ hastanın başlangıç CRP düzeyleri normalden yüksek idi. $39(\% 49,4)$ hasta omalizumab tedavi öncesinde sistemik steroid kullanmış iken, $10(\% 12,7)$ hasta da immünsupresif (siklosporin) kullanma öyküsü mevcuttu. $9(\% 11,4)$ hastanın astım öyküsü mevcuttu.

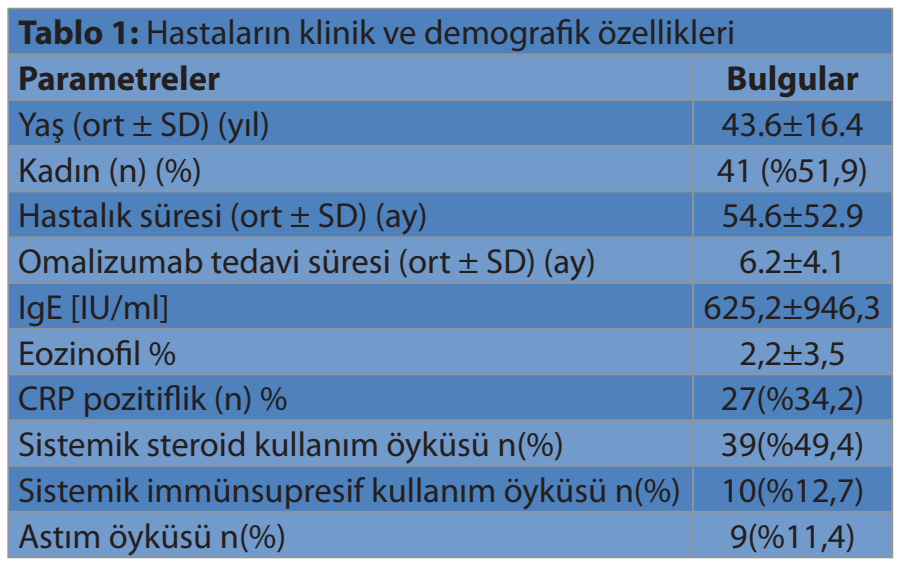

Omalizumab tedavisi 3. ayı sonunda hastaların yapılan değerlendirilmesinde, 14 (19.7\%) hastada tam yanıt, 36 (50.7\%) hastada kısmı yanıt görülürken, $21(\% 29,6)$ hastada yanıt alınamadı (Şekil 1). Tedavi esnasında kaydedilen yan etkiler incelendiğinde sadece iki (2,8\%) hastada uygulama bölgesinde lokal eritem tespit edildi. İlaç ile ilişkili olduğu düşünülen sistemik bir yan etki görülmedi. Hastaların takiplerinde klinik değerlendirilmesinde ve fizik muayenesinde herhangi bir sorun saptanmadı. Omalizumab tedavisinin iyi tolere edildiği tespit edildi.

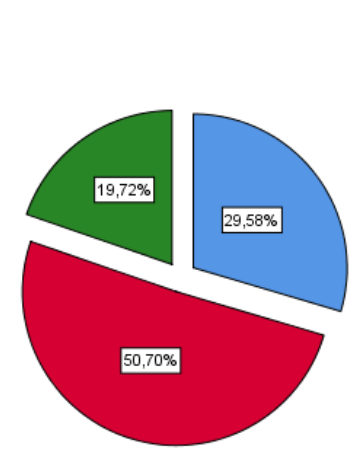

Şekil 1. Omalizumab tedavisinin 3. ay sonunda hastaların değerlendirilmesine göre elde edilen sonuçlar

Başlangıç total lgE, eozinofil, bazofil ve CRP düzeyleri, hastalık süresi, hasta yaşı, cinsiyeti, astım öyküsü ve immünsupresif kullanım öyküsü açısından 3. ay sonu omalizumab tedavisi yanıt grupları 
arasında herhangi bir istatistiksel farklılık tespit edilmedi ( $p>0.05)$. Hasta dosyaları incelendiğinde $22(\% 30,9)$ hastanın halen ilaç kullanımına devam etmekte olduğu tespit edildi. Tedaviye devam etmekte olan iki hastada yetersiz yanıt nedeni ile omalizumab dozunun iki katına çıkarıldığı tespit edildi. Yine tedaviye devam etmekte olan üç hastanın ise omalizumab tedavisine ek olarak siklosporin kullandığı tespit edildi. Tedaviyi bırakan $25(\% 35,2)$ hastada tam remisyon gözlendiği için tedavinin kesildiği saptandı. $15(\% 21,1)$ hastanın ise tedavi yanıtsızlığı nedeni ile tedaviyi bıraktığı tespit edildi. 8 (\%11,3) hastanın ise tedaviyi bırakma sonrasında antihistaminik kullanmaya devam eden kısmi yanıtlı olan hastalar olduğu tespit edildi.

\section{Tartışma}

Kronik spontan ürtiker; kronik ve nükseden seyri, nükslerin öngörülemezliği ve şiddetli kaşıntılı lezyonlar nedeni ile genellikle hastalar üzerinde ağır bir psikososyal yük oluşturur.[10] Tedavinin amacı hastalığa bağlı semptomları yan etkileri olmayan tedavilerle kontrol etmektir. Tedavide ilk seçenek olarak ikinci nesil ve sedatizasyon özelliği olmayan $\mathrm{H} 1$ bloke edici antihistaminikler tercih edilmektedir. Bununla birlikte, hastaların önemli bir oranı yüksek dozlarda antihistaminiklere yanıtsız seyretmektedir. Son yıllarda ise antihistaminiklere yanıtsız KSÜ hastalarında bir antiIgE monoklonal antikoru olan omalizumab, tedavi kılavuzları tarafından etkili ve güvenli bir ajan olarak önerilmektedir.[11]

Erken faz 2 ve faz 3 randomize plasebo kontrollü, çok merkezli çalışmalarda $\mathrm{H} 1$ antihistaminikleri lisanslı dozlarda daha önce kullanılmasına rağmen halen semptomatik olan KSÜ hastalarında omalizumabın semptomları kontrol etmede yararlı etkinlik gösterdiği saptanmıştır.[12,13] Maurer ve ark.'nın [13] 2013 yılında yaptıkları faz 3 çok merkezli randomize çift kör çalışma ile Metz ve ark.'nın [14] 4 yıllık retrospektif analizinde hem KSÜ hem de kronik indüklenebilir ürtiker hastalarında omalizumab tedavisinin hızlı, yüksek oranda etkili ve güvenilir bir tedavi seçeneği olduğu sonucuna varılmıştır. Yapılan pek çok gerçek yaşam çalışmasına rağmen günümüzde omalizumab tedavisinin ne kadar sürmesi ve nasıl kesilmesi gerektiği ve uzun dönem yan etkileri gibi bir takım soru işaretleri halen mevcuttur. Bu nedenle daha fazla sayıda gerçek yaşam verisi içeren çalışmaya ihtiyaç halen devam etmektedir. Bu çalışmada omalizumab kullanan KSÜ hastalarının gerçek yaşam verilerinin belirlenmesi amaçlanmıştır ve dirençli KSÜ'de omalizumabın güvenli ve etkili bir tedavi seçeneği olduğu gözlenmiş olup bu sonuçlar bugüne kadarki literatür verilerini destekler niteliktedir.

Bu çalışmada 3 ay sonunda 14 (19.7\%) hastada tam yanıt, 36 (50.7\%) hastada kısmi yanıt görülürken, 21 (\%29,6) hastada yanıt alınamadığı tespit edilmiştir. Omalizumab kullanan hastalarda gerçek yaşam verilerinin değerlendirildiği ve 45 çalışmanın dâhil edildiği ve 1158 hastanın sonuçlarının değerlendirildiği son bir metaanalizde \%30 ile 100 arasında değişen ve ortalaması \%76 olarak tespit edilen tam yanıt oranları bildirilmiştir.[15]. Ülkemizde yapılan gerçek yaşam verilerinin değerlendirildiği çalışmalarda ise elde edilen tam yanıt oranları \%13,3 ile \%76,9 arasında değişmektedir.[8,9, 16-19] Literatürde elde edilen farklı sonuçların çalışmalarda hastalara uygulanan omalizumab dozlarının farklı olmasına, klinik yanıtın değerlendirilme farklılıklarına ve etnik farklılıklara bağlı olabileceğini düşünmekteyiz. Bazı çalışmalarda klinik cevap yanıt var veya yok şeklinde sınıflandırılırken, bazı çalışmalarda ise klinik yanıt çalışmamızda olduğu gibi tam yanıt, kısmi yanıt ve yanıtsız şeklinde sınıflandırma yapılmıştır.[15] Ayrıca yapılan çalışmaların çoğunda kullanılan ek tedavilerle ilgili bilgilendirme eksikliği tespit edilmiştir.[20] Çalışma sonuçlarında ki farkııı̆ın bir nedenide ülkelerin sağlık bakanlıklarının farklı geri ödeme politikaları olabileceğini düşünmekteyiz. Ülkemizde omalizumab daha önce en az 6 ay süreyle antihistaminik tedavisi almış ancak yanıt alınamamış olan hastalarda geri ödeme kapsamındadır.

Bu çalışmada yan etki olarak sadece iki hastada ilacın uygulandığı bölgede lokal eritem görüldü, bu hastaların fiziksel incelemesinde ve takiplerinde herhangi bir sorun tespit edilmedi. Bunun dışında omalizumab ile ilişkili yan etki görülmedi. Tedavi iyi tolere edildi. Literatürde astım ve KSÜ de omalizumab tedavisinin güvenilir olduğu birçok derleme, metanaliz ve çalışmada gösterilmiştir.[3-9] Astımın aksine, KSÜ'de omalizumab dozu IgE seviyelerinden bağımsız olarak ayarlanmaktadır. Omalizumab'a tam yanıt verenlerde, semptomları bastırmak için gerekli doz ile toplam serum IgE seviyeleri arasında herhangi bir korelasyon saptanmamıştır ve omalizumab tedavisinin etkinliğinin başlangıç total IgE değerlerinden bağımsız olduğu düşünülmektedir.[14] Bu çalışmada yine literatürle uyumlu olarak klinik iyileşmenin başlangıç total IgE düzeylerinden bağımsız olduğu gözlendi.[17,19] Hastalarda tedavi etkinliğinin, hastaların başlangıç IgE değerlerinden çok zaman içerisinde gözlenen lgE artışı ile korelere olduğu yine son zamanlarda yapılan bir çalışmada saptanmıştır.[21]

Bu çalışmanın üstünlükleri, geriye dönük olarak gerçek yaşam deneyimlerini aktarması ve hasta popülasyonunun heterojen olmasıdır. Ek olarak omalizumab kullanım süresinin $6.2 \pm 4.1$ ay ile yeterli bir süre olduğunu görmekteyiz. Çalışmanın kısıtlılıkları ise tek merkezli bir çalışma olması ve geriye dönük bir çalışma olması nedeni ile hastaların ürtiker aktivite skorlarının değerlendirilmemiş olmasıdır. 


\section{Sonuç}

Bu çalışmada, kendi hastanemizde KSÜ nedeniyle takip edip omalizumab verdiğimiz hastalarda, omalizumab tedavisinin oldukça etkin ve yan etki açısından da güvenilir olduğunu tespit ettik.

\section{Çıkar çatışması/finansal destek beyanı}

Bu yazıdaki hiçbir yazarın herhangi bir çıkar çatışması yoktur. Yazının herhangi bir finansal desteği yoktur.

\section{Kaynaklar}

1. Antia C, Baquerizo K, Korman A, Bernstein JA, Alikhan A. Urticaria: A comprehensive review: Epidemiology, diagnosis, and work-up. J Am Acad Dermatol 2018; 79: 599-614.

2. Poonawalla T, Kelly B. Urticaria : a review. Am J Clin Dermatol 2009; 10: 9-21.

3. Zuberbier, T, Aberer W, Asero R et al. The EAACI/GA(2) LEN/EDF/ WAO Guideline for the definition, classification, diagnosis, and management of urticaria: the 2013 revision and update. Allergy 2014; 69: 868-87.

4. Chang T.W, Chen C, Lin C.J, Metz M, Church M.K, Maurer M. The potential pharmacologic mechanisms of omalizumab in patients with chronic spontaneous urticaria. J Allergy Clin Immunol 2015; 135: 337-42.

5. D'Amato G. Role of anti-IgE monoclonal antibody (omalizumab) in the treatment of bronchial asthma and allergic respiratory diseases. Eur J Pharmacol 2006; 533: 302-7.

6. Lai T, Wang S, Xu Z et al. Long-term efficacy and safety of omalizumab in patients with persistent uncontrolled allergic asthma: a systematic review and meta-analysis. Sci Rep 2015; 5: 8191.

7. Corren J, Casale T, Lanier B, Buhl R, Holgate S, Jimenez P. Safety and tolerability of omalizumab. Clin Exp Allergy 2009; 39: 788-97.

8. Tat TS. Kronik spontan ürtikerde omalizumab tedavisinin etkinliği ve güvenliği. Cukurova Med J 2018; 43: 903-7.

9. Nazik H, Mülayim MK, Öztürk P. Omalizumab usage in chronic urticaria and atopic dermatitis: data from South-East province of Turkey. Postepy Dermatol Alergol 2019; 36: 734-8.

10. Balp MM, Khalil S, Tian H, Gabriel S, Vietri J, Zuberbier T. Burden of chronic urticaria relative to psoriasis in five European countries. J Eur Acad Dermatol Venereol 2018; 32: 282-90.
11. Zuberbier $T$, Aberer $W$, Asero $R$ et al. The EAACI/GA(2) LEN/EDF/ WAO Guideline for the definition, classification, diagnosis, and management of urticaria: the 2013 revision and update. Allergy 2014; 69: 868-87.

12. Saini S, Rosen $\mathrm{KE}, \mathrm{Hsieh} \mathrm{HJ}$ et al. A randomized, placebo-controlled, dose-ranging study of single-dose omalizumab in patients with $\mathrm{H} 1$-antihistamine-refractory chronic idiopathic urticaria. J Allergy Clin Immunol 2011; 128: 567-73.

13. Maurer M, Rosén $\mathrm{K}, \mathrm{H}$ sieh $\mathrm{HJ}$ et al. Omalizumab for the treatment of chronic idiopathic or spontaneous urticaria. N Engl J Med 2013; 368: 924-35.

14. Metz M, Ohanyan T, Church MK, Maurer M. Omalizumab is an effective and rapidly acting therapy in difficult-to-treat chronic urticaria: a retrospective clinical analysis. J Dermatol Sci 2014; 73: 57-62.

15. Tharp MD, Bernstein JA, Kavati A et al. Benefits and Harms of Omalizumab Treatment in Adolescent and Adult Patients With Chronic Idiopathic (Spontaneous) Urticaria: A Meta-analysis of "Real-world" Evidence. JAMA Dermatol 2019; 155: 29-38.

16. Türk M, Yılmaz İ, Bahçecioğlu SN. Treatment and retreatment with omalizumab in chronic spontaneous urticaria: Real life experience with twenty-five patients. Allergol Int 2018; 67: 85-9.

17. Engin B, Çelik U, Birben AÖ et al. Omalizumab in chronic spontaneous urticaria treatment: Real life experiences Turkderm-Turk Arch Dermatol Venereology 2019; 53: 145-9

18. Akyol A, Öktem A, Akay BN, Kundakçı N, Boyvat A. Omalizumab and treatment-resistant chronic spontaneous urticaria. Turkderm 2015; 49: 180-3.

19. Türkmen $M$, Çoban $M$, Doğan $S$ et al. Kronik spontan ürtikerde omalizumab tedavisinin etkinliği: Retrospektif değerlendirilme. Turkderm-Turk Arch Dermatol Venereology 2019; 53: 65-7.

20. Bernstein JA, Kavati A, Tharp MD et al. Effectiveness of omalizumab in adolescent and adult patients with chronic idiopathic/spontaneous urticaria: a systematic review of 'realworld'evidence. Expert Opin Biol Ther 2018; 18: 425-48.

21. Ertas R, Ozyurt K, Atasoy M, Hawro T, Maurer M. The clinical response to omalizumab in chronic spontaneous urticaria patients is linked to and predicted by IgE levels and their change. Allergy 2018; 73: 705-12. 